Gut and Liver, Vol. 12, No. 1, January 2018, pp. 7-16

\title{
Current Trends in the Management of Gastroesophageal Reflux Disease
}

\author{
Dalbir S. Sandhu and Ronnie Fass
}

The Esophageal and Swallowing Center, Division of Gastroenterology and Hepatology, MetroHealth Medical Center, Case Western Reserve University, Cleveland, OH, USA

Gastroesophageal reflux disease (GERD) characterized by heartburn and/or regurgitation symptoms is one of the most common gastrointestinal disorders managed by gastroenterologists and primary care physicians. There has been an increase in GERD prevalence, particularly in North America and East Asia. Over the past three decades proton pump inhibitors (PPIs) have been the mainstay of medical therapy for GERD. However, recently there has been an increasing awareness amongst physicians and patients regarding the side effects of the PPI class of drugs. In addition, there has been a marked decline in the utilization of surgical fundoplication as well as a rise in the development of nonmedical therapeutic modalities for GERD. This review focuses on different management strategies for GERD, optimal management of refractory GERD with special focus on available endoluminal therapies and the future directions. (Gut Liver

\section{8;12:7-16)}

Key Words: Gastroesophageal reflux; Proton pump inhibitors; Heartburn; Surgery

\section{INTRODUCTION}

The American College of Gastroenterology (ACG) guidelines define gastroesophageal reflux disease (GERD) as "symptoms or complications resulting from the reflux of gastric contents into the esophagus or beyond, into the oral cavity (including larynx) or lung." ${ }^{1}$ Erosive esophagitis (EE), nonerosive reflux disease (NERD) and Barrett's esophagus are the three phenotypic presentations of GERD. ${ }^{2}$ In general, patients tend to remain within their phenotypic presentation throughout their lifetime with very little progression or regression.

GERD is a common disease with the highest prevalence in North America. A systematic review demonstrated that the prevalence of GERD ranged from $18.1 \%$ to $27.8 \%$ in North America, $8.8 \%$ to $25.9 \%$ in Europe, $2.5 \%$ to $7.8 \%$ in East Asia, 8.7\% to 33.1\% in the Middle East, $11.6 \%$ in Australia, and 23.0\% in South America. ${ }^{3}$

The cardinal symptoms of GERD are heartburn and regurgitation. ${ }^{4}$ However, GERD may present with a variety of other symptoms, including water brash, chest pain or discomfort, dysphagia, belching, epigastric pain, nausea, and bloating. In addition, patients may experience extraesophageal symptoms like cough, hoarseness, throat clearing, throat pain or burning, wheezing, and sleep disturbances.

Studies have demonstrated that symptom frequency, severity, or combination of both are not predictive of any specific phenotypic presentation of GERD. ${ }^{5}$ However, elderly patients with GERD appear to experience a more severe mucosal disease that is associated with overall milder and more atypical symptoms. ${ }^{6}$

Most patients with typical symptoms of GERD receive empiric treatment with a proton pump inhibitor (PPI) and do not undergo diagnostic testing. However, in patients with alarm symptoms such as dysphagia, odynophagia, anorexia, weight loss and upper gastrointestinal bleed, investigation with an upper endoscopy is warranted. The use of other diagnostic tests, such as catheter based $\mathrm{pH}$ test, wireless $\mathrm{pH}$ capsule, impedance $+\mathrm{pH}$ and others are reserved for specific clinical scenarios when further management is needed in patients who partially or showed complete lack of response to PPI treatment. The last decade has seen some major changes in the landscape of GERD treatment, a growing number of reports about adverse events due to longterm use of PPIs, a marked decline in the utilization of surgical fundoplication and the rise in the development of nonmedical therapeutic options.

The following review is focused on the current management of GERD including medical, endoscopic, and surgical therapeutic modalities as well as future directions (Table 1).

\footnotetext{
Correspondence to: Ronnie Fass

The Esophageal and Swallowing Center, Division of Gastroenterology and Hepatology, MetroHealth Medical Center, Case Western Reserve University, 2500 MetroHealth Drive, Cleveland, OH 44109, USA

Tel: +1-216-778-3145, Fax: +1-216-778-2074, E-mail: ronnie.fass@gmail.com Received on December 28, 2016. Accepted on January 6, 2017. Published online April 24, 2017 pISSN 1976-2283 eISSN 2005-1212 https://doi.org/10.5009/gnl16615

@) This is an Open Access article distributed under the terms of the Creative Commons Attribution Non-Commercial License (http://creativecommons.org/licenses/by-nc/4.0) which permits unrestricted non-commercial use, distribution, and reproduction in any medium, provided the original work is properly cited.
} 
Table 1. Currently Available Therapeutic Modalities for Gastroesophageal Reflux Disease

\begin{tabular}{|c|c|}
\hline Type of therapy & Subtype \\
\hline \multirow[t]{3}{*}{ Lifestyle modifications } & Raising head end of the bed \\
\hline & Avoiding meals within 3 hours of bedtime \\
\hline & Weight loss \\
\hline \multirow[t]{7}{*}{ Medical } & Antacids \\
\hline & Gaviscon \\
\hline & Proton pump inhibitors \\
\hline & $\mathrm{H} 2$ receptor antagonists \\
\hline & Prokinetics \\
\hline & Baclofen \\
\hline & Carafate \\
\hline \multirow[t]{2}{*}{ Surgical } & Fundoplication \\
\hline & $\operatorname{Linx}^{\mathrm{TM}}$ magnetic ring \\
\hline \multirow[t]{2}{*}{ Endoluminal therapies } & Transoral incisionless fundoplication \\
\hline & Stretta \\
\hline
\end{tabular}

\section{LIFESTYLE MODIFICATIONS}

Lifestyle modifications remain the cornerstone of any therapeutic intervention for GERD, which is commonly overlooked by physicians and not followed by patients. While patients report that tobacco, chocolate, carbonated beverages, onion, tomato sauce, mint, alcohol, citrus juices, spicy and fatty meals exacerbate their GERD related symptoms, we are still devoid of high quality trials providing clear evidence for the value of avoiding these food products or habits. A systematic review of clinical trials that examined the impact of lifestyle modifications on GERD by change in symptoms, esophageal $\mathrm{pH}$ variables, or lower esophageal sphincter basal pressure showed that there is either lack of or weak evidence that after cessation of tobacco, alcohol, chocolate, caffeine or coffee, citrus, mint or spicy food there is improvement in clinical or physiological parameters of GERD.

Obesity has been demonstrated to be an important risk factor for the development or worsening of GERD. A large cohort study from the United States comprising 10,545 women demonstrated that any increase in body mass index (BMI) in individuals of normal weight was associated with an increased risk of GERD. Even modest weight gain can exacerbate GERD symptoms and women who reduced their BMI by 3.5 units or more reported a 40\% reduction in the frequency of GERD symptoms compared with controls. ${ }^{8}$ Thus weight loss appears to be an effective lifestyle modification in improving GERD. Importantly, lifestyle modifications associated with sleep have been shown to improve GERD related symptoms and even heal mild EE (Table 2). ${ }^{9}$ In addition to elevating the head of the bed, patients should avoid eating at least 3 hours prior to sleep time, and
Table 2. Therapeutic Approaches for Nighttime Gastroesophageal Reflux Disease

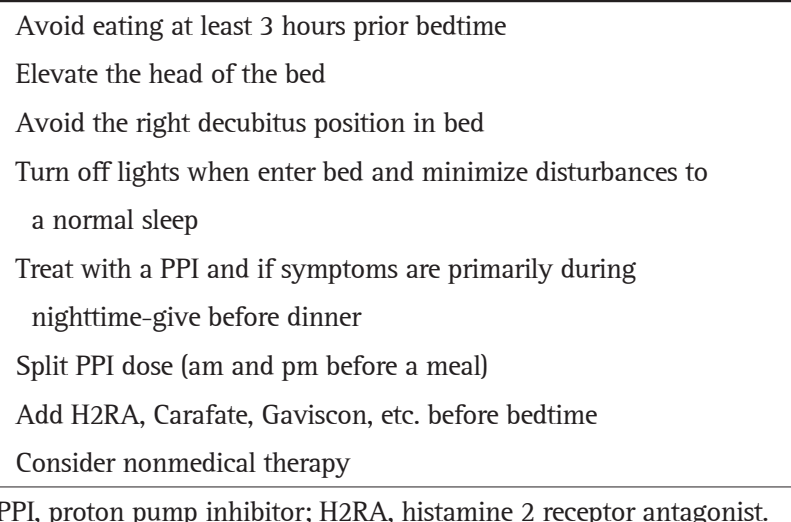

the right decubitus position during sleep. Furthermore, patients should improve their sleep hygiene, because sleep reduces gastroesophageal reflux by suppressing transient lower esophageal sphincter relaxations (TLESRs). ${ }^{10}$ Physicians should recommend additional lifestyle modifications based on patient's report and avoid a "laundry list" of recommendations, which are unlikely to be followed by the average GERD patient.

\section{Medical therapy}

In patients who continue to have bothersome GERD-related symptoms despite lifestyle modifications, medical therapy is commonly offered or used. Medical therapy includes, antacids, Gaviscon, histamine 2 receptor antagonists (H2RAs), PPIs, Carafate, TLESR reducer, and prokinetics.

PPIs are considered the most effective medical therapy for GERD, due to their profound and consistent acid suppression (Table 3). The first compound in this class of drugs, omeprazole, was introduced in the late 1980's. Overall, PPIs are safe and demonstrate different levels of satisfaction that range between $56 \%$ to $100 \%$ as compared with other antireflux medications. ${ }^{11}$ PPIs are the most widely prescribed medication for both EE and NERD, although systematic reviews have shown that patients with NERD respond less well to PPIs than those with EE. ${ }^{12}$

Several large scale studies have shown that PPI treatment is superior to H2RA treatment for the symptomatic relief of both EE and NERD patients. ${ }^{13}$ Importantly, there were no statistically significant differences in the rate of adverse events between PPIs and H2RAs, or PPIs and placebo. The overall rate of symptomatic relief of PPIs in NERD patients has been shown to reach 51.4\% (95\% confidence interval [CI], 0.433 to 0.595 ; $\mathrm{p}=0.0001) .{ }^{14}$ PPI therapy is better when compared to combination of H2RA plus prokinetic in healing EE (relative risk [RR], $0.51 ; 95 \%$ CI, 0.44 to 0.59). Interestingly, prokinetic therapy is not better than placebo in healing of EE (RR, 0.71; 95\% CI, 0.46 to 1.10). The aforementioned studies as well as others cemented the superiority of PPIs over any other medical therapy for GERD in controlling symptoms, healing $\mathrm{EE}$, and preventing relapse of 
Table 3. Currently Available Proton Pump Inhibitors

\begin{tabular}{lllcl}
\hline & & \multicolumn{1}{c}{ Brand name } & Dose, mg & OTC \\
\hline 1 & Omeprazole & Prilosec, Prilosec OTC & $10,20,40$ & Yes \\
2 & Esomeprazole & Nexium & 20,40 & Yes \\
3 & Lansoprazole & Prevacid, Prevacid 24 hr & 15,30 & Yes \\
4 & Rabeprazole & AcipHex & 10,20 & No \\
5 & Pantoprazole & Protonix & 20,40 & No \\
6 & Dexlansoprazole & Dexilant & 30,60 & No \\
7 & Omeprazole with sodium bicarbonate & Zegerid, Zegerid OTC & 20,40 & Yes \\
\hline
\end{tabular}

PPI, proton pump inhibitor; OTC, over the counter.

both symptoms and esophageal inflammation. ${ }^{15}$

PPIs are also the most effective medical therapy as compared to all the other medical therapies in controlling symptoms of the various phenotypic presentations of GERD. In particular, PPIs significantly improve symptom response rate as compared with H2RAs in patients with NERD. ${ }^{16}$

Since the introduction of omeprazole, six additional PPIs have been introduced into the market. Most only slightly differ in their structure from each other. Some of these newer PPIs (Lansoprazole, Rabeprazole, and Pantoprazole) were compared with omeprazole in controlling heartburn and healing EE. A meta-analysis of these studies concluded that the newer PPIs were of similar efficacy to omeprazole in terms of heartburn control, healing EE, and relapse rates. All the PPIs were found to be superior to ranitidine and placebo in healing and decreasing relapse rates of $\mathrm{EE}^{17}$

Presently in the United States, four of these PPIs are available over the counter (Omeprazole, Lansoprazole, Esomeprazole and Omeprazole-sodium bicarbonate) and three can only be obtained by a prescription (Dexlansoprazole, Pantoprazole, and Rabeprazole). Esomeprazole is the S-enantiomer of omeprazole and was Food and Drug Administration (FDA) approved in 2001. A 2006 meta-analysis evaluated esomeprazole versus the other PPIs (omeprazole, lansoprazole, and pantoprazole) in the healing of EE. At 4 weeks and 8 weeks, there was a 10\% and 5\% (RR, 1.05; 95\% CI, 1.02 to 1.08) relative increase in the probability of healing. At 8 weeks there was an absolute risk reduction of 4\% and the number needed to treat (NNT) was 25 . As compared with omeprazole, lansoprazole, and pantoprazole, esomeprazole provided a statistically significant improvement but clinically only a modest overall benefit in EE healing and symptom relief. Additionally, the clinical benefit of esomeprazole appears negligible in mild erosive disease (NNT of 50) but more pronounced in severe EE (NNT of 8). The PPIs appear to have similar efficacy. ${ }^{18}$ However, Dexlansoprazole, a dual delayed release PPI that provides prolonged concentration time profile and extended duration of acid suppression, has been shown to be effective as a sole PPI in patients who require standard dose PPI twice daily to control their symptoms. ${ }^{19}$
The value of continuous treatment with a PPI versus an on demand or intermittent therapy remains controversial. Several studies reported that continuous treatment yields a greater patients' satisfaction than on-demand therapy. However, others have demonstrated that on-demand therapy is superior to continuous treatment in patients with mild GERD because it is less costly, relieves concern about chronic use of PPIs and overall patients are highly satisfied. ${ }^{20,21}$

In summary, based on the current evidence PPIs can provide symptom relief in approximately 57\% to 80\% of patients with EE and about 50\% of the patients with NERD. In addition, healing of $\mathrm{EE}$ (all grades) can be obtained in greater than $85 \%$ of GERD patients undergoing treatment with a standard dose PPI. However, randomized controlled trials (RCTs) are efficacy studies, reporting the beneficial effect of a medication under carefully controlled conditions. ${ }^{22}$ Under "real world circumstances," many factors may affect response to treatment (effectiveness), such as, access to treatment, accuracy of diagnosis, acceptance of intervention and adherence to treatment. ${ }^{23}$ Thus, response to PPI treatment in clinical practice is unlikely to follow the same success rates as those reported by RCTs. Poor compliance, lack of adherence to correct time of PPI administration and incorrect diagnosis are some of the important hurdles that plague successful treatment of GERD patients in clinical practice. ${ }^{24}$

\section{Optimization of PPI therapy}

According to ACG guidelines, the first step in the management of refractory GERD is optimization of PPI therapy (Table 4). ${ }^{1}$ Thus, improving compliance with PPI treatment is an important initial step for optimization of PPI treatment. The prescribing providers should educate their patients about the importance of taking the PPI daily in order to achieve maximum effect. A recent study has shown that compliance with a PPI was the highest if the medication was prescribed by a gastroenterologist and the lowest if patients obtained their PPI over the counter. ${ }^{25}$ Adherence to proper timing of PPI consumption is also an important step in PPI optimization. A study has demonstrated that 100\% of the patients who were refractory to PPI once daily were not consuming the PPI optimally (30 minutes prior to a 
Table 4. Steps for Optimization of Proton Pump Inhibitor Treatment

Lifestyle modifications
Improve compliance
Ensure proper dosing time
Split the PPI dose
Switch to another PPI

PPI, proton pump inhibitor.

meal). ${ }^{26}$ Instead, they were consuming it more than an hour before a meal, during a meal and at bedtime. Thus, it is important to explain to patients about proper timing of PPI consumption for maximum effect.

Another important step in optimizing PPI treatment is the continuous need to follow life style modifications related to GERD. ${ }^{7}$ Overall, there is no PPI that patients cannot "out eat." Thus, regardless of PPI consumption, patients should consider avoiding large, spicy and fatty meals, lose weight and embark on nighttime precautions (elevating the head of the bed, avoid eating at least 3 hours prior to bedtime and follow guidelines for good sleep hygiene).

Interestingly, recent studies have shown that spreading the PPI dose during the day improves control of intragastric $\mathrm{pH}$. A study reported that the median intragastric $\mathrm{pH}$ was $4.8,5.7$, and 6.6 with Rabeprazole given $40 \mathrm{mg}$ once daily, $20 \mathrm{mg}$ twice daily or $10 \mathrm{mg}$ four times daily, respectively. ${ }^{27}$ However, spreading the PPI dose throughout the day may reduce compliance.

The evidence for the value of doubling the PPI dose in improving symptom control of patients who failed once daily PPI therapy remains limited to a very few studies. In a group of 96 GERD patients who failed omeprazole $20 \mathrm{mg}$ once daily, only 26.1\% demonstrated some type of a response to omeprazole 40 $\mathrm{mg}$ daily compared to $22.7 \%$ on lansoprazole $30 \mathrm{mg}$ twice daily $(\mathrm{p}=\mathrm{NS}) .^{28}$ However, another study showed that the rate of EE healing and specifically early healing was significantly higher in patients receiving $40 \mathrm{mg}$ pantoprazole versus $20 \mathrm{mg}$ or 10 mg daily, regardless of EE severity. ${ }^{29}$ Comparison of Omeprazole $40 \mathrm{mg}$ versus $20 \mathrm{mg}$ daily showed a statistically significant difference in the healing of $E E(p=0.05)$ at 4 weeks; however, this difference was lost at 8 weeks $(p=0.10)$. Additionally healing was influenced by severity of EE at entry level with fewer than half of grade D EE patients healed with either 20 or $40 \mathrm{mg}$ of omeprazole. $^{30}$

\section{Refractory heartburn}

Refractory heartburn is defined as symptoms of reflux of gastric content that do not respond to a double dose of a PPI given for at least 8 weeks. ${ }^{31}$ Successful treatment of refractory heartburn depends on the underlying mechanism. Fig. 1 depicts the management algorithm and the different therapeutic options in heartburn patients who failed PPI treatment.

Recent studies have shown that most patients with refrac- tory heartburn or other typical GERD symptoms, often do not have GERD as the underlying cause. ${ }^{32}$ The commonly implicated mechanisms include functional heartburn and reflux hypersensitivity. Psychological comorbidity (anxiety, hypervigilance, depression, and somatization) does play an important role in patients with refractory heartburn. In addition, several other mechanisms including compliance, improper dosing time, concomitant functional bowel disorder, delayed gastric emptying, eosinophilic esophagitis, bile reflux, residual acid and nonacid reflux, rapid PPI metabolism, PPI resistance may play a role in varying degree in refractory heartburn. Overlap of these mechanisms can further add to the complexity of refractory heartburn. ${ }^{33}$ Importantly, patients who failed once daily PPI are more likely to have advanced grading of EE, NERD, reflux hypersensitivity, or functional heartburn in comparison to patients who failed twice daily PPI who are more likely to have reflux hypersensitivity and functional heartburn. ${ }^{34}$

Medical options for patients who are poorly controlled on twice daily PPI are very limited. In patients who continue to demonstrate an abnormal esophageal acid exposure on twice daily PPI, the addition of an H2RA at bedtime has gained popularity after studies have demonstrated an improved overnight intragastric $\mathrm{pH}$ control. However, the effect appears to be short lived as tachyphylaxis develops very quickly when daily dosing of H2RA is used. ${ }^{35}$

Baclofen, a gamma-aminobutyricacid-B agonist has shown promising results in the management of refractory GERD patients with residual acid or weakly acidic reflux (abnormal levels or normal levels but positive correlation with symptoms) by reducing the rate of TLESR and thus gastroesophageal reflux. ${ }^{36,37}$ Neurological side effects such as dizziness, tiredness, sleepiness are commonly reported with the use of baclofen. Less common side effects are nausea, diarrhea, and flatulence. A metaanalysis reported no serious adverse events or deaths related to the use of baclofen in GERD patients. In addition, there were no significant differences in the overall adverse events between baclofen and placebo. All reported side effects of baclofen were of mild-to-moderate intensity, and the drug was well tolerated. The study also supported the value of baclofen in treating GERD patients, who failed PPI twice daily, but continued to demonstrate residual reflux as the underlying cause of their symptoms. ${ }^{38}$ Although not approved by the FDA for GERD, a trial of 5 to $20 \mathrm{mg}$ of Baclofen three times a day can be considered in GERD patients not effectively controlled by twice daily PPI, who continued to demonstrate residual gastroesophageal reflux.

Because reflux hypersensitivity and functional heartburn are by far the leading causes for refractory heartburn, diagnosis and treatment of these disorders should be initially considered. These patients are commonly managed with neuro-modulators which include, tricyclic antidepressants, selective serotonin reuptake inhibitors, serotonin-norepinephrine reuptake inhibitors and trazodone. 


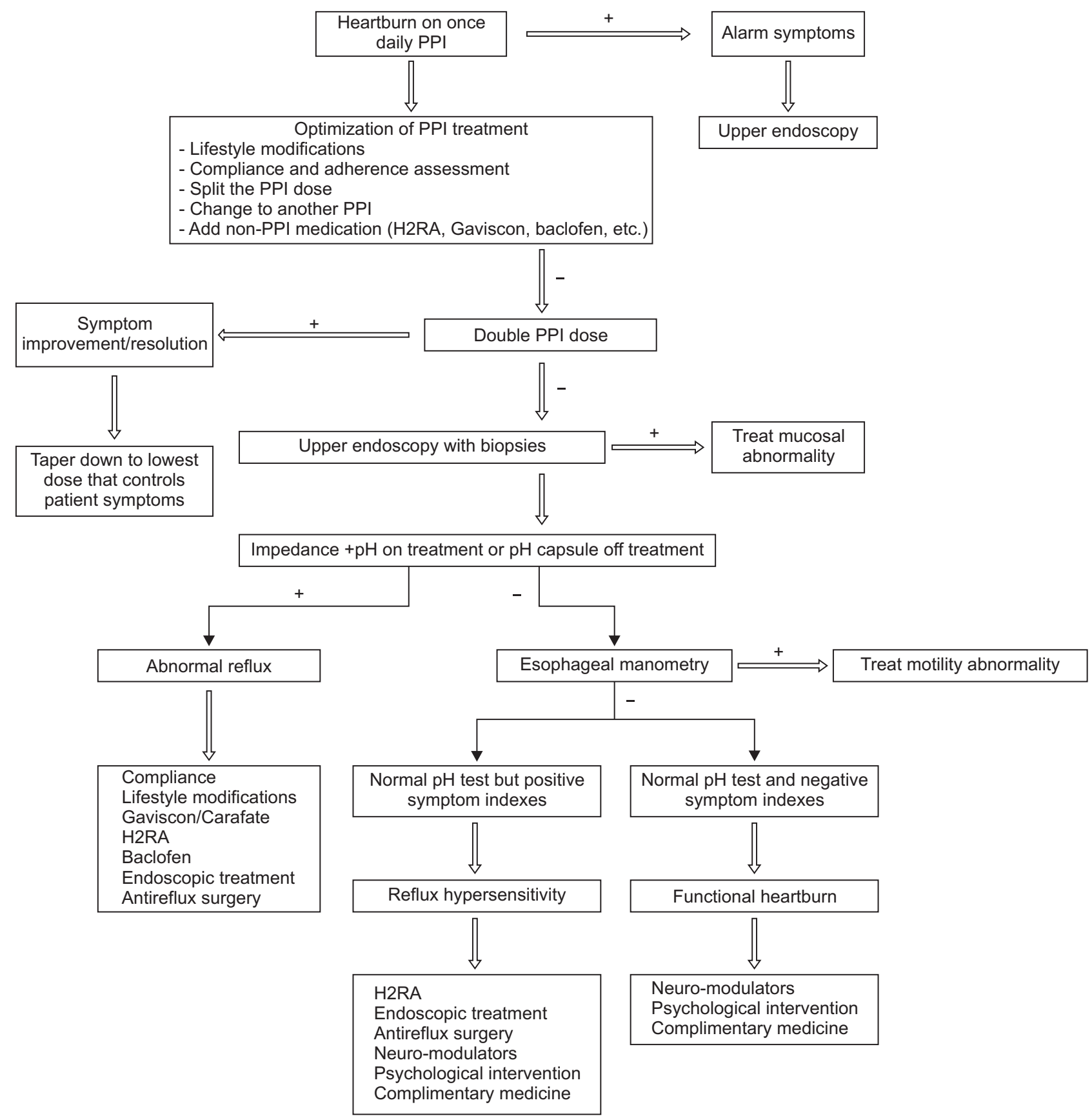

Fig. 1. Management algorithm of heartburn patients who failed treatment with proton pump inhibitor (PPI) once daily. H2RA, histamine 2 receptor antagonists.

Proposed sequence for managing patients with refractory heartburn is to begin with impedance plus $\mathrm{pH}$ study if patients have documented history of GERD (abnormal pH test or EE on endoscopy) or wireless pH capsule if there is no history of GERD. Patients with a normal test (any of the 2 mentioned above) but demonstrate positive indexes should be considered having reflux hypersensitivity. Those with normal tests and negative symptoms indexes should be considered having functional heartburn.

Treatment of refractory heartburn is focused on evaluation of PPI dosing time and compliance, possibly adding H2RA at bedtime (if symptoms correlate with acid reflux), considering a TLESR reducer such as Baclofen. ${ }^{39}$ Other nonpharmacological options could be considered, such as endoscopic treatment or antireflux surgery. In patients with functional heartburn or reflux hypersensitivity neuro-modulators are the cornerstone of treatment.

\section{Side effects of PPIs}

PPIs have long been considered a safe class of drugs however, 
in the last decade a rush of publications reported a variety of side effects due to long term treatment like nutritional deficiencies (magnesium, vitamin $\mathrm{B}_{12}$ ), increased risk of gastroenteritis, travelers' diarrhea, Clostridium difficile colitis, osteoporosis and bone fracture, microscopic colitis, ischemic heart disease, chronic kidney injury and dementia. Recent data demonstrated an increased incidence of chronic kidney dysfunction secondary to acute interstitial nephritis in patients receiving PPIs. The risk was higher with twice daily than once daily dosing. ${ }^{40}$ More recently, PPIs have been shown to increase the levels of $\beta$-amyloid in the brain of mice. Furthermore, a large prospective cohort study showed a significant increased risk of dementia in patients on PPI compared to patients not receiving PPI. ${ }^{41}$ Overall, the risk of any of the aforementioned side effects due to long-term treatment with a PPI is relatively modest. Because almost all of the studies reporting these side effects are population based, it is unclear if any of the aforementioned retrospective reports will be confirmed in a prospective trial. Regardless, patients should receive the lowest dose of PPI that control their symptoms, the need for chronic PPI treatment should be evaluated on a regular basis and alternative options to chronic PPI treatment should be sought out in patients with high risk for PPI-related adverse events.

\section{Surgical treatment for GERD}

Several surgical techniques are currently available for the treatment of GERD. However, a recent study demonstrated a rapid decline in the rate of utilization of surgical fundoplication in the United States between 2004 and 2013 to the level seen in 2004. Overall, there was a rise in the utilization of antireflux surgery from 2004 until 2009 but a steady decline since then with a significant trend $(\mathrm{p}=0.044)$. The rate in 2013 of surgical fundoplication's performed was $0.047 \%$, similar to the percentage a decade before (0.041\%). Additionally, the use of PPI and H2RA postsurgical fundoplication has been steadily increasing over the past 4 years (PPI, 80\%; H2RA, 52\%). Overall, PPI use postsurgical fundoplication has increased from 45\% in 2010 to $80 \%$ in $2013 .^{42}$

Patients who are candidates for antireflux surgery, should undergo $\mathrm{pH}$ testing prior to the procedure if they have normal endoscopy and no history of prior $\mathrm{pH}$ testing. Additionally, all patients should undergo high resolution esophageal manometry prior to surgery to rule out achalasia or other esophageal motor disorders, such as absent contractility. Patients with typical heartburn that is fully controlled on a PPI or those who demonstrate an abnormal ambulatory $\mathrm{pH}$ monitoring with a positive symptom correlation appear to have the best surgical outcome. Atypical or extraesophageal symptoms of GERD tend to show less response to surgical therapy. Candidates for surgical fundoplication include subjects who are not interested, concerned about, developed adverse events and who are unable to comply with regular, long term medical treatment. In addition, those with still abnormal $\mathrm{pH}$ test while on maximum PPI dose, symptoms of regurgitation, large hiatal hernia $(>5 \mathrm{~cm})$ and possibly those with symptoms associated with nonacid reflux (Table 5).

Laparoscopic surgical fundoplication is presently the most common technique performed in GERD patients. Current data lend a level 1a support for the use of laparoscopic posterior approach as the surgical treatment of choice for GERD. The prevalence of heartburn, PPI use and reoperation rate is higher after the laparoscopic anterior approach. ${ }^{43,44}$

Comparative studies between antireflux surgery and medical therapy demonstrated mixed results in patients with GERD. A large meta-analysis that included seven trials showed that surgical treatment of GERD is more effective than medical therapy with respect to patient-relevant outcomes in both the short and medium term. Heartburn and regurgitation were less frequent after surgical intervention. However, a considerable proportion of patients still needed antireflux medication after surgical fundoplication. Patients who underwent surgery were significantly more likely to be satisfied with their symptom control and also showed a higher satisfaction rate with the treatment received. ${ }^{45}$ However, a recently published Cochrane review that included a total of 1,160 participants in four RCTs who were randomly assigned to laparoscopic fundoplication (589 patients) or medical treatment with a PPI (571 patients) demonstrated that there is a considerable uncertainty in the balance of benefits versus harms of laparoscopic fundoplication when compared to longterm medical treatment with a PPI. The authors recommended that further RCTs of laparoscopic fundoplication versus medical management in patients with GERD should be conducted with an outcome-assessor blinding to achieve a more conclusive recommendation. Such trials should include long-term patientorientated outcomes such as treatment-related adverse events (including severity), quality of life, and also report on the social and economic impact of the adverse events and symptoms. ${ }^{46,47}$

A recent addition to the surgical repertoire for GERD is the Linx $^{\mathrm{TM}}$ reflux management system. The device consists of a series of titanium beads with a magnetic core connected with titanium wires to form a ring. This ring is placed around the lower end of the distal esophagus by laparoscopy and it helps

Table 5. Candidates for Surgical Therapy

Side effects from medical therapy
Poor compliance with medical therapy
Concern about or wish to discontinue chronic medical therapy
Symptomatic with a large hiatal hernia
Regurgitation
Not interested in medical therapy
Abnormal pH test on maximum PPI dose
Symptoms correlate with nonacid reflux while on maximum PPI dose

PPI, proton pump inhibitor. 
to augment the lower esophageal sphincter and thus prevent gastroesophageal reflux. The initial experience of the $\operatorname{Lin}^{\mathrm{TM}}$ device in a small series of carefully selected patients $(n=100)$ have shown normalization of esophageal acid exposure or a 50\% or greater reduction in acid exposure at 1 year in 64\% of the patients (95\% CI, 54 to 73). A reduction in PPI usage and overall improvement in quality of life was reported in greater than 90\% of patients. The most frequent adverse event was dysphagia in $68 \%$ of the patients. ${ }^{48}$ When compared to Nissen fundoplication, the $\operatorname{Linx}^{\mathrm{TM}}$ device has shown similar improvement in quality of life and symptomatic relief, with fewer side effects, but lower PPI elimination rates. ${ }^{49}$ Although the initial results are promising, the long term efficacy, durability and safety of the device has yet to be proved in larger group of patients.

\section{ENDOLUMINAL THERAPIES FOR GERD}

Over the last 20 years, researchers have focused on the development of endoluminal therapies for the management of GERD. The endoscopic techniques are less invasive and safer than surgical fundoplication with the aim of achieving similar efficacy rates. In addition, there is decreased reliance on PPIs or other oral medications used for GERD. The original endoluminal therapies have been broadly categorized to four different types; (1) fixation, (2) ablation, (3) injection, (4) mucosal excision and suturing. Today, only two endoluminal techniques are available in the market, the Stretta and Esophy $\mathrm{X}^{\circledR}$. The Esophy $\mathrm{X}^{\circledR}$ device, also known as transoral incisionless fundoplication (TIF), is used to restore the angle of His by creating a valve at the esophagogastric junction (EGJ). This is achieved by delivering multiple full thickness, nonabsorbable fasteners at the EGJ. Since its first use in 2005, about 17,000 TIF procedures have been done. The Randomized EsophyX versus Sham Placebo-Controlled Trial (RESPECT), a multicenter study conducted at eight centers in the United States, reported that TIF provided better control of heartburn than the sham procedure off medication. ${ }^{50}$ The findings were further supported by the TIF EsophyX versus Medical PPI Open Label (TEMPO) trial that reported elimination of troublesome regurgitation in 97\% and 93\% of the TIF patients at 6 and 12 months follow-up period, respectively. ${ }^{51,52}$ The long-term efficacy of TIF has been tested in a small group of 50 carefully selected symptomatic GERD patients followed for up to 6 years. The TIF procedure achieved a long lasting elimination of daily dependence on PPI treatment in 75\% to $80 \%$ of the patients. ${ }^{53}$ Ideal candidates for the TIF procedure are patients with chronic GERD (abnormal pH test or low grade EE) who have absent or small hiatal hernia $(\leq 2 \mathrm{~cm})$.

Another multicenter trial randomly assigned patients with GERD and hiatal hernias $\leq 2 \mathrm{~cm}$ to groups that underwent TIF and then received 6 months of placebo $(n=87)$, or sham surgery and 6 months of once- or twice-daily omeprazole (controls, $n=42$ ). By intention-to-treat analysis, TIF provided a complete relief of troublesome regurgitation in a larger proportion of patients (67\%) than PPI treatment (45\%) $(\mathrm{p}=0.023)$. Subjects from both groups who completed the protocol had similar reductions in GERD symptom scores with rarely experiencing severe complications. $^{54}$

A recent RCT comparing TIF versus sham intervention to control chronic GERD also showed that TIF is effective in chronic PPI-dependent GERD patients when followed for up to 6 months. $^{50}$

Even though TIF has been around for several years, the newer technique has been shown to have an excellent safety profile. With increasing number of centers performing TIF, it is likely to gain popularity in the near future for the management of carefully selected GERD patients.

Another endoscopic technique for GERD that has been around longer than the TIF procedure is the Stretta procedure. The Stretta device is a balloon-tipped four-needle catheter that delivers radiofrequency energy into the smooth muscle of the EGJ. The first published report in 2001 showed promising results of the Stretta procedure in 25 patients with GERD. ${ }^{55}$ Over the last 16 years this therapeutic modality has markedly improved and has been used in more than 20,000 patients.

A recent systematic review that included all four RCTs comparing the Stretta procedure to sham, has concluded that the procedure was not more efficacious than sham intervention. ${ }^{56}$ The earlier RCTs were critiqued to be of poor methodological quality. However, a long-term follow-up of patients who underwent the Stretta procedure was recently published by Noar et $a{ }^{57}$ The authors performed a 10-year, open label, prospective follow-up of patients with refractory GERD who were treated with the Stretta procedure. Out of 217 that reached the 10-year follow-up, 72\% had normalization of health-related quality of life and 64\% had greater than 50\% reduction in baseline PPI use with discontinuation in $41 \%$ at the 10 -year mark. Despite the conflicting results current evidence suggests that the Stretta procedure is an effective therapeutic modality for patients with GERD.

\section{FUTURE DIRECTIONS}

Drug development in the GERD arena has markedly declined, due to the overall feeling that no other medication can surpass PPIs. At the same time, there are still many areas of unmet need in GERD, providing a unique opportunity for drug development. Furthermore, the growing number of reports about the different adverse events of long-term PPI treatment drive patients to seek alternative therapeutic options. Consequently, endoluminal therapy for GERD and antireflux surgical techniques may see a rise in patients' interest, which may lead to further development of new and minimally invasive nonmedical interventions. 


\section{CONCLUSIONS}

GERD is a very common disorder and can be managed effectively in a large number of patients with combination of life style modifications and appropriate medical therapy. Managing refractory GERD, which can be seen in up to $40 \%$ of the patients receiving PPI once daily, can be challenging. The best initial approach is optimization of PPI therapy. A careful history and use of investigative tools can help identify the contributing factors for PPI failure. In patients with residual reflux, medications like $\mathrm{H} 2$ blockers, Prokinetics and baclofen may be used. In those with functional heartburn or reflux sensitivity neuromodulators form an integral part of any therapeutic approach. Surgical fundoplication for GERD is still performed but the rate of utilization has been markedly decreasing in recent years. Endoluminal therapies provide an efficacious symptomatic control in a subset of patients and serve as a good alternative to medical or surgical treatment.

\section{CONFLICTS OF INTEREST}

Ronnie Fass-Advisor-Mederi therapeutics, ethicon speakerAstrazeneca Takeda, Dr. Redely.

\section{REFERENCES}

1. Katz PO, Gerson LB, Vela MF. Guidelines for the diagnosis and management of gastroesophageal reflux disease. Am J Gastroenterol 2013;108:308-328.

2. Fass R, Ofman JJ. Gastroesophageal reflux disease: should we adopt a new conceptual framework? Am J Gastroenterol 2002;97:1901-1909.

3. El-Serag HB, Sweet S, Winchester CC, Dent J. Update on the epidemiology of gastro-oesophageal reflux disease: a systematic review. Gut 2014;63:871-880.

4. Nasrollah L, Maradey-Romero C, Jha LK, Gadam R, Quan SF, Fass R. Naps are associated more commonly with gastroesophageal reflux, compared with nocturnal sleep. Clin Gastroenterol Hepatol 2015;13:94-99.

5. Fass R. Non-erosive reflux disease (NERD) and erosive esophagitis: a spectrum of disease or special entities? Z Gastroenterol 2007;45:1156-1163.

6. Poh $\mathrm{CH}$, Navarro-Rodriguez T, Fass R. Review: treatment of gastroesophageal reflux disease in the elderly. Am J Med 2010;123:496-501.

7. Kaltenbach T, Crockett S, Gerson LB. Are lifestyle measures effective in patients with gastroesophageal reflux disease? An evidence-based approach. Arch Intern Med 2006;166:965-971.

8. Jacobson BC, Somers SC, Fuchs CS, Kelly CP, Camargo CA Jr. Body-mass index and symptoms of gastroesophageal reflux in women. N Engl J Med 2006;354:2340-2348.

9. Fass $R$. The relationship between gastroesophageal reflux disease and sleep. Curr Gastroenterol Rep 2009;11:202-208.

10. Fujiwara Y, Arakawa T, Fass R. Gastroesophageal reflux disease and sleep disturbances. J Gastroenterol 2012;47:760-769.

11. Chey WD, Mody RR, Izat E. Patient and physician satisfaction with proton pump inhibitors (PPIs): are there opportunities for improvement? Dig Dis Sci 2010;55:3415-3422.

12. Dean BB, Gano AD Jr, Knight K, Ofman JJ, Fass R. Effectiveness of proton pump inhibitors in nonerosive reflux disease. Clin Gastroenterol Hepatol 2004;2:656-664.

13. Chiba N, De Gara CJ, Wilkinson JM, Hunt RH. Speed of healing and symptom relief in grade II to IV gastroesophageal reflux disease: a meta-analysis. Gastroenterology 1997;112:1798-1810.

14. Zhang JX, Ji MY, Song J, et al. Proton pump inhibitor for nonerosive reflux disease: a meta-analysis. World J Gastroenterol 2013;19:8408-8419.

15. Khan M, Santana J, Donnellan C, Preston C, Moayyedi P. Medical treatments in the short term management of reflux oesophagitis. Cochrane Database Syst Rev 2007;(2):CD003244.

16. Sigterman KE, van Pinxteren B, Bonis PA, Lau J, Numans ME. Short-term treatment with proton pump inhibitors, H2-receptor antagonists and prokinetics for gastro-oesophageal reflux diseaselike symptoms and endoscopy negative reflux disease. Cochrane Database Syst Rev 2013;(5):CD002095.

17. Caro JJ, Salas M, Ward A. Healing and relapse rates in gastroesophageal reflux disease treated with the newer proton-pump inhibitors lansoprazole, rabeprazole, and pantoprazole compared with omeprazole, ranitidine, and placebo: evidence from randomized clinical trials. Clin Ther 2001;23:998-1017.

18. Gralnek IM, Dulai GS, Fennerty MB, Spiegel BM. Esomeprazole versus other proton pump inhibitors in erosive esophagitis: a meta-analysis of randomized clinical trials. Clin Gastroenterol Hepatol 2006;4:1452-1458.

19. Fass R, Inadomi J, Han C, Mody R, O’Neil J, Perez MC. Maintenance of heartburn relief after step-down from twice-daily proton pump inhibitor to once-daily dexlansoprazole modified release. Clin Gastroenterol Hepatol 2012;10:247-253.

20. van Zanten SJ, Henderson C, Hughes N. Patient satisfaction with medication for gastroesophageal reflux disease: a systematic review. Can J Gastroenterol 2012;26:196-204.

21. Jiang YX, Chen Y, Kong X, Tong YL, Xu SC. Maintenance treatment of mild gastroesophageal reflux disease with proton pump inhibitors taken on-demand: a meta-analysis. Hepatogastroenterology 2013;60:1077-1082.

22. Compher C. Efficacy vs effectiveness. JPEN J Parenter Enteral Nutr 2010;34:598-599.

23. El-Serag HB, Talwalkar J, Kim WR. Efficacy, effectiveness, and comparative effectiveness in liver disease. Hepatology 2010;52:403-407.

24. Hershcovici T, Fass R. Step-by-step management of refractory gastresophageal reflux disease. Dis Esophagus 2013;26:27-36.

25. Sheikh I, Waghray A, Waghray N, Dong C, Wolfe MM. Consumer use of over-the-counter proton pump inhibitors in pa- 
tients with gastroesophageal reflux disease. Am J Gastroenterol 2014;109:789-794.

26. Gunaratnam NT, Jessup TP, Inadomi J, Lascewski DP. Sub-optimal proton pump inhibitor dosing is prevalent in patients with poorly controlled gastro-oesophageal reflux disease. Aliment Pharmacol Ther 2006;23:1473-1477.

27. Sugimoto M, Shirai N, Nishino M, et al. Rabeprazole $10 \mathrm{mg}$ q.d.s. decreases 24 - $h$ intragastric acidity significantly more than rabeprazole $20 \mathrm{mg}$ b.d. or $40 \mathrm{mg}$ o.m., overcoming CYP2C19 genotype. Aliment Pharmacol Ther 2012;36:627-634.

28. Fass R, Murthy U, Hayden CW, et al. Omeprazole $40 \mathrm{mg}$ once a day is equally effective as lansoprazole $30 \mathrm{mg}$ twice a day in symptom control of patients with gastro-oesophageal reflux disease (GERD) who are resistant to conventional-dose lansoprazole therapy-a prospective, randomized, multi-centre study. Aliment Pharmacol Ther 2000;14:1595-1603.

29. Richter JE, Bochenek W. Oral pantoprazole for erosive esophagitis: a placebo-controlled, randomized clinical trial. Pantoprazole US GERD Study Group. Am J Gastroenterol 2000;95:3071-3080.

30. Hetzel DJ, Dent J, Reed WD, et al. Healing and relapse of severe peptic esophagitis after treatment with omeprazole. Gastroenterology 1988;95:903-912.

31. Fass R. Therapeutic options for refractory gastroesophageal reflux disease. J Gastroenterol Hepatol 2012;27 Suppl 3:3-7.

32. Herregods TV, Troelstra M, Weijenborg PW, Bredenoord AJ, Smout AJ. Patients with refractory reflux symptoms often do not have GERD. Neurogastroenterol Motil 2015;27:1267-1273.

33. Fass R, Sifrim D. Management of heartburn not responding to proton pump inhibitors. Gut 2009;58:295-309.

34. Hershcovici T, Fass R. Nonerosive reflux disease (NERD): an update. J Neurogastroenterol Motil 2010;16:8-21.

35. Fackler WK, Ours TM, Vaezi MF, Richter JE. Long-term effect of H2RA therapy on nocturnal gastric acid breakthrough. Gastroenterology 2002;122:625-632.

36. Grossi L, Spezzaferro M, Sacco LF, Marzio L. Effect of baclofen on oesophageal motility and transient lower oesophageal sphincter relaxations in GORD patients: a 48-h manometric study. Neurogastroenterol Motil 2008;20:760-766.

37. Koek GH, Sifrim D, Lerut T, Janssens J, Tack J. Effect of the GABA(B) agonist baclofen in patients with symptoms and duodeno-gastro-oesophageal reflux refractory to proton pump inhibitors. Gut 2003;52:1397-1402.

38. Li S, Shi S, Chen F, Lin J. The effects of baclofen for the treatment of gastroesophageal reflux disease: a meta-analysis of randomized controlled trials. Gastroenterol Res Pract 2014;2014:307805.

39. Hershcovici T, Fass R. Management of gastroesophageal reflux disease that does not respond well to proton pump inhibitors. Curr Opin Gastroenterol 2010;26:367-378.

40. Lazarus B, Chen Y, Wilson FP, et al. Proton pump inhibitor use and the risk of chronic kidney disease. JAMA Intern Med 2016;176:238-246.

41. Gomm W, von Holt K, Thomé F, et al. Association of proton pump inhibitors with risk of dementia: a pharmacoepidemiological claims data analysis. JAMA Neurol 2016;73:410-416.

42. Khan F, Maradey-Romero C, Ganocy S, Frazier R, Fass R. Utilisation of surgical fundoplication for patients with gastro-oesophageal reflux disease in the USA has declined rapidly between 2009 and 2013. Aliment Pharmacol Ther 2016;43:1124-1131.

43. Broeders JA, Roks DJ, Ahmed Ali U, Draaisma WA, Smout AJ, Hazebroek EJ. Laparoscopic anterior versus posterior fundoplication for gastroesophageal reflux disease: systematic review and metaanalysis of randomized clinical trials. Ann Surg 2011;254:39-47.

44. Memon MA, Subramanya MS, Hossain MB, Yunus RM, Khan S, Memon B. Laparoscopic anterior versus posterior fundoplication for gastro-esophageal reflux disease: a meta-analysis and systematic review. World J Surg 2015;39:981-996.

45. Rickenbacher N, Kötter T, Kochen MM, Scherer M, Blozik E. Fundoplication versus medical management of gastroesophageal reflux disease: systematic review and meta-analysis. Surg Endosc 2014;28:143-155.

46. Garg SK, Gurusamy KS. Laparoscopic fundoplication surgery versus medical management for gastro-oesophageal reflux disease (GORD) in adults. Cochrane Database Syst Rev 2015;(11):CD003243.

47. Hatlebakk JG, Zerbib F, Bruley des Varannes S, et al. Gastroesophageal acid reflux control 5 years after antireflux surgery, compared with long-term esomeprazole therapy. Clin Gastroenterol Hepatol 2016;14:678-685.e3.

48. Ganz RA, Peters JH, Horgan S, et al. Esophageal sphincter device for gastroesophageal reflux disease. N Engl J Med 2013;368:719727.

49. Warren HF, Reynolds JL, Lipham JC, et al. Multi-institutional outcomes using magnetic sphincter augmentation versus Nissen fundoplication for chronic gastroesophageal reflux disease. Surg Endosc 2016;30:3289-3296.

50. Håkansson B, Montgomery M, Cadiere GB, et al. Randomised clinical trial: transoral incisionless fundoplication vs. sham intervention to control chronic GERD. Aliment Pharmacol Ther 2015;42:1261-1270.

51. Trad KS, Barnes WE, Simoni G, et al. Transoral incisionless fundoplication effective in eliminating GERD symptoms in partial responders to proton pump inhibitor therapy at 6 months: the TEMPO Randomized Clinical Trial. Surg Innov 2015;22:26-40.

52. Trad KS, Simoni G, Barnes WE, et al. Efficacy of transoral fundoplication for treatment of chronic gastroesophageal reflux disease incompletely controlled with high-dose proton-pump inhibitors therapy: a randomized, multicenter, open label, crossover study. BMC Gastroenterol 2014;14:174.

53. Testoni PA, Testoni S, Mazzoleni G, Vailati C, Passaretti S. Longterm efficacy of transoral incisionless fundoplication with Esophyx (Tif 2.0) and factors affecting outcomes in GERD patients followed for up to 6 years: a prospective single-center study. Surg Endosc 2015;29:2770-2780.

54. Hunter JG, Kahrilas PJ, Bell RC, et al. Efficacy of transoral fundo- 
16 Gut and Liver, Vol. 12, No. 1, January 2018

plication vs omeprazole for treatment of regurgitation in a randomized controlled trial. Gastroenterology 2015;148:324-333.e5.

55. Richards WO, Scholz S, Khaitan L, Sharp KW, Holzman MD. Initial experience with the stretta procedure for the treatment of gastroesophageal reflux disease. J Laparoendosc Adv Surg Tech A 2001;11:267-273.

56. Lipka S, Kumar A, Richter JE. No evidence for efficacy of radiofre- quency ablation for treatment of gastroesophageal reflux disease: a systematic review and meta-analysis. Clin Gastroenterol Hepatol 2015;13:1058-1067.

57. Noar M, Squires P, Noar E, Lee M. Long-term maintenance effect of radiofrequency energy delivery for refractory GERD: a decade later. Surg Endosc 2014;28:2323-2333. 